\title{
EDUCAÇÃO A DISTÂNCIA NO CONTEXTO DA PANDEMIA DA COVID-19: UMA ALTERNATIVA DEMOCRÁTICA OU SEGREGADORA?
}

Jardel Delgado Marques ${ }^{\mathrm{i}}$

RESUMO: O tema desse artigo é uma reflexão a respeito da Educação a Distância (EaD) no período atípico vivido pela pandemia da COVID-19, possibilitando um debate acerca da prática democrática ou segregadora que a modalidade exerce na educação básica. Analisa-se a temática à luz de pensadores brasileiros que defendem a ideia da educação como grande instrumento de transformação social e emancipação do sujeito, além de buscar fundamentos na história da Educação e na obra "Pedagogia do Oprimido", de Paulo Freire, servindo para apontar possíveis caminhos para a prática educativa libertadora, visando a emancipação do sujeito a partir de um posicionamento mais crítico. Ademais, o presente artigo visa oferecer um debate atual e que reforça a ideia de que a educação não deve servir aos interesses de uma classe hegemônica, mas garantir o acesso democrático a todos. Aponta-se que as escolas públicas, deverão sofrer fortes aportes para a implementação eficiente dessa modalidade de ensino, de forma a não criar um abismo entre o ensino público e privado.

Palavras-chave: Educação pública, Educação a Distância, Dualidade Educacional, Paulo Freire

\section{DISTANCE EDUCATION IN THE PANDEMIC CONTEXT OF COVID-19: A DEMOCRATIC OR SEGREGATOR ALTERNATIVE?}

ABSTRACT: The theme of this article is a reflection on Distance Education (DE) in the atypical period experienced by the COVID-19 pandemic, enabling a debate about the democratic or segregating practice that the modality exercises in basic education. The theme is analyzed in the light of Brazilian thinkers who defend the idea of education as a great instrument of social transformation and emancipation of the subject, in addition to looking for foundations in the history of Education and in the work "Pedagogia do Oprimido", by Paulo Freire, serving to to point out possible paths for liberating educational practice, aiming at the subject's emancipation from a more critical position. In addition, this article aims to offer a current debate that reinforces the idea that education should not serve the interests of a hegemonic class, but should guarantee democratic access for all. It is pointed out that public schools should suffer strong contributions for the efficient implementation of this type of teaching, in order not to create an abyss between public and private education.

Key-words: Public education, Distance Education, Educational Duality, Paulo Freire 


\section{Introdução}

O atual cenário social imposto pela pandemia do novo coronavírus (COVID-19), leva a destacar inúmeras desigualdades sociais que atravessam o Brasil, dentre essas pode-se evidenciar a dualidade do sistema educacional brasileiro, considerando a Educação a Distância $(\mathrm{EaD})$ quando implantada às pressas na educação básica, não alcança a todas as unidades escolares e estudantes e, com isso, acaba por ser um elemento segregador.

Assim, o presente artigo busca refletir sobre a dualidade educacional que se tornou ainda mais evidente nesse período de pandemia, pois, de um lado, a rede privada buscou meios para continuar suas atividades, enquanto que a rede pública ainda caminha a passos lentos e difíceis na implementação da modalidade a distância, considerando as dificuldades sócio-econômicas dos alunos para acompanhar o processo educativo nesses tempos.

Tal ideia ainda pode ser evidenciada no que postula Campello (2008, p. 136), “a escola não é única, nem unificadora, mas constituída pela unidade contraditória de duas redes de escolarização [...]". Desse modo, o que torna-se notória é a dicotomia do sistema de educação do Brasil, fruto de iniciativas de ordem capitalista e intervenções ineficientes do Estado.

Segundo Frigotto (2003, p. 153), o modelo de educação pública reflete na "retirada do conhecimento sobre o fazer e o pensar dos trabalhadores [...]”. Assim, o que se percebe é o reforço da ideia de uma qualidade inferior aplicada à educação pública, como uma maneira de oferecer a formação que servirá aos interesses da classe dominante. Com isso, a educação pública ganha uma projeção negativa e minimalista, onde os seus alunos se veem fadados a servir aos interesses dominantes.

Ademais, é possível compreender que a ação educativa destinada à classe trabalhadora sofre duros golpes desde a sua idealização, não representando o verdadeiro valor que a educação deve desempenhar na sociedade. Com isso, o novo período, atravessado pela pandemia do coronavírus, apenas reforça a ideia precária e sem relevância que a educação pública assume nas pautas atuais.

Por isso, a escola pública obedece a uma lógica contraditória, como assevera Saviani (1994, p.05): "Quanto mais avança o processo urbano-industrial, mais se desloca a exigência da expansão escolar [...] esta sociedade moderna e burguesa levanta a bandeira da escolarização universal, gratuita, obrigatória e leiga".

Desse modo, o presente artigo busca refletir os entraves pedagógicos que o novo período impulsiona na atual sociedade, buscando embasamento teórico em pensadores e filósofos brasileiros que se dedicam a área educacional e social, bem como possibilitar uma reflexão acerca da educação como uma poderosa arma de transformação social. 
Assim, é apresentado um breve comentário da educação pública destinada às camadas populares, buscando reforço nos escritos de autores brasileiros. São apresentados também alguns breves comentários e citações referentes à modalidade da Educação a Distância (EaD) no Brasil. Por fim, são relacionados os comentários desse trabalho com a obra de Paulo Freire, "A Pedagogia do Oprimido", buscando traçar paralelos e reforçando a ideia de saída, através da educação de qualidade, para o problema oriundo desse período da pandemia da COVID-19.

\section{Um breve retrato da educação pública: de sua origem até os tempos atuais}

Muitos autores dedicaram-se a refletir e criticar o modelo pedagógico visto na sociedade brasileira, dentre esses autores pode-se destacar as contribuições de Demerval Saviani. Em suas obras mais reconhecidas, é possível encontrar elementos que fornecem o nascimento e o contexto do surgimento da escola pública. Tais dados servem de base para que se possa compreender os reais objetivos e motivos da educação pública representar o que é na atualidade.

Decerto, Saviani (2007, p.154) postula que "o ato de agir sobre a natureza transformando-a em função das necessidades humanas é o que conhecemos com o nome de trabalho". Com isso, pode-se compreender a real formulação teórica que o trabalho adquire no contexto social, apresentando relação direta com a necessidade humana de se impor no meio social e a formação desse novo modelo de sociedade.

Logo, o processo educativo surge da necessidade de transferir conhecimento às gerações mais novas, possibilitando o ingresso para o meio social. Assim, ele pode ser encarado como uma preparação para a vida em sociedade, tendo em vista que, a partir do momento em que o homem deixa de ser nômade e passa a depender ainda mais da natureza para sobreviver, ele precisa se adaptar e agir sobre tudo o que está ao seu redor.

Segundo Saviani (1995), a educação aparece como uma condição humana de sobrevivência, uma vez que os homens não têm sua existência garantida pela natureza, ou seja, precisam pensar em formas de adaptação ao meio social. Assim, o processo educativo surge como instrumento de ensinar às gerações futuras, a partir da reprodução dos conceitos incutidos ao longo dos tempos.

Nos primeiros momentos, existia a educação, mas não existia a escola, tal como uma instituição de preparação para a vida. Contudo, a forma de ensinar já sofria uma diferenciação em sua gênese, fato que perdurou ao longo dos anos.

Se a divisão social e técnica do trabalho é condição indispensável para a constituição do modo capitalista de produção, à medida em que, rompendo a unidade entre teoria e prática, prepara diferentemente os homens para que atuem em posições hierárquica e tecnicamente diferenciadas 
no sistema produtivo. [...] a educação diretamente articulada ao trabalho se estrutura como um sistema diferenciado e paralelo ao sistema de ensino regular marcado por finalidade bem específica: a preparação dos pobres, marginalizados e desvalidos da sorte para atuarem no sistema produtivo nas funções técnicas localizadas nos níveis baixo e médio da hierarquia ocupacional. (KUENZER, 1991, p.8)

A citação, retirada do livro da Dra. Acácia Zeneida Kuenzer, apesar de antiga, torna-se muito atemporal, porque traduz a realidade precária do sistema educacional brasileiro, além de traçar um olhar que percorreu todos esses anos e choca-se com o período em que transcorre a pandemia do coronavírus, em pleno ano de 2020. Portanto, evidencia-se que a educação pública no Brasil ainda necessita de maiores incentivos e aportes, de forma a traçar novos rumos e que desmistifiquem essa tese de que a educação serve aos interesses da produção capitalista, fornecendo apenas mão-de-obra barata às indústrias.

Desse modo, como se observa em Kuenzer (1991) é que a escola está subordinada à indústria, articulando um trabalho pedagógico que está embasado na lógica econômica e na formação de força produtiva para os níveis mais baixos hierarquicamente. Com esse exemplo, pode-se perceber que não há uma preocupação com a formação cidadã e global dos estudantes, filhos da classe trabalhadora, o que se espera é que eles continuem a perpetuar essa oposição social e escolar.

À vista disso, Alves (2019, p. 03, grifos do autor) aponta que "a escola surge em determinado momento histórico e social como uma modalidade específica de educação diferenciada da educação em geral pela qual passavam as gerações anteriores.”

Assim, na concepção dos primeiros modelos educativos, pensava-se em dividir a forma de como os conhecimentos deveriam ser repassados, levando em conta a origem de cada criança. Sendo assim, as crianças de origem mais privilegiada receberiam ensinamentos que versariam para o trabalho intelectual e, posteriormente, serviriam para que pudessem perpetuar o legado de suas famílias abastadas e ainda dirigir o trabalho daqueles que estavam sob seu jugo. Em contrapartida, as crianças da classe dos nãoproprietários receberiam ensinamentos chamados de Artes Mecânicas, pois o conhecimento que receberiam seria o de dirigir utilizando a força física e as mãos. Nesse sentido, a escola já surge refletindo uma clara diferenciação dos conteúdos e da forma de lecionar.

Conforme postula Saviani (2007)

\footnotetext{
"A educação dos membros da classe que dispõe de ócio, de lazer, de tempo livre passa a organizarse na forma escolar, contrapondo-se à educação da maioria, [...] a separação entre escola e produção reflete, por sua vez, a divisão que se foi processando ao longo da história entre trabalho manual e trabalho intelectual." (SAVIANI, 2007, p. 156 e 157)
}

Alves (2020, p. 48) ainda levanta o seguinte questionamento: “A defesa da educação escolar para todos, inclusive para a classe trabalhadora, coloca para a burguesia o problema de em que medida isto deveria ser feito?" 
É possível compreender que a educação foi idealizada para servir aos interesses da classe dominante, a burguesia, sem considerar os anseios e desejos da classe trabalhadora. Desse modo, cabe entender que a educação pública foi estruturada em ditames oriundos das intenções capitalistas, favorecendo a desigualdade social e a formação em caráter inferior à classe trabalhadora.

De acordo com Alves (2020, p. 48), “a burguesia, ao criar a escola pública no processo de consolidação do novo modo de produção (capitalista), não considerou a participação dos trabalhadores na elaboração do modelo [...]”. Essa participação da classe trabalhadora foi evitada, para que os conhecimentos a serem ofertados fossem aqueles que melhor se adequassem ao que almejavam para legitimar o modo de produção capitalista.

\begin{abstract}
Daí se explica o porquê de se criar uma modelo de escola "para" e não "com" a classe trabalhadora. Este modelo foi pensado a partir dos interesses dos capitalistas, para atender às suas necessidades de acumulação ampliada do capital, pouco interessando a formação humana e intelectual dos trabalhadores a seu serviço. Concebe-se o ser que trabalha apenas como mão-deobra útil ao capital, em detrimento de ele ser também um ser humano e tudo que isto implica do ponto de vista de sua educação e emancipação humana. (ALVES, 2019, p. 4-5)
\end{abstract}

A partir das epígrafes acima de Dalton Alves, pode apreender que o modelo de educação pública, conforme se vê na atualidade, convém ao sistema capitalista, enfatizando a sua lógica do lucro acima do bem comum, assim como a formação de mão-de-obra para abastecimento do mercado de trabalho.

Ainda de acordo com Alves (2019, p. 10), "quando se comenta da má qualidade da escola pública popular, deve-se entender que esta não é de má qualidade, e sim, que ela tem a qualidade que interessa ao sistema para a classe trabalhadora".

Diante dessas concepções, a educação pode ser vista como um mero instrumento que destaca as diferenças sociais, uma vez que, desde a sua concepção, ela foi planejada com objetivos claros que favorecem a lógica capitalista e a formação despicienda da classe dominada, em favor dos interesses da elite.

Desse modo, na atualidade pode-se perceber essa diferenciação no que tange o ensino a distância oferecido nas escolas públicas de educação básica. De um lado, percebe-se que as escolas privadas oportunizam Ambiente Virtual de Aprendizagem (AVA) através de uma plataforma interativa e que oferece ensino remoto aos seus alunos. Ao passo que, as escolas públicas buscam outros meios menos eficientes, traduzindo a precariedade do serviço e o baixo incentivo com a educação pública. Tal exemplo ilustra a temática histórica proposta até aqui, colaborando para asseverar que o ensino destinado à classe trabalhadora não está na pauta atual dos interesses políticos.

Logo, a função da prática educativa, como instrumento de ampliação da cidadania, sofre frequentes golpes anti-democráticos, tal como aponta Saviani (1994, p.05), que "a escola entra nesse processo contraditório: ela é reivindicada pelas massas trabalhadoras, mas as camadas dominantes 
relutam em expandi-la". Com isso, reflete-se os interesses da classe dominante no subjugo da classe trabalhadora.

Logo, a contradição mais indiscutível foi a própria formulação de uma escola que era pensada para as pessoas, e não, com as pessoas a que se destinariam. Dessa forma, a escola seguiria o ponto de vista daqueles que a idealizavam, objetivando um conhecimento mais apurado e intelectual para a classe dirigente, em oposição, a um conhecimento inferior para aqueles que assumiriam as posições de ingresso imediato ao mercado de trabalho.

É sabido que a escola pública, apesar de ser idealizada pela premissa da igualdade e democracia, na atualidade não reflete uma oferta democrática e de qualidade, levando em consideração a dicotomia que acompanha a prática educativa desde a sua gênese. Apesar dos grandes esforços docentes, a educação pública ainda é sucateada por políticas públicas e decisões que não a consideram um elemento de transformação social.

Assim, compreender o processo histórico da educação pública é algo fundamental, para que se possa saber os verdadeiros interessados e, dessa forma, buscar soluções afirmativas e que assegurem o acolhimento social e a diminuição das diferenças a partir do chão da escola. Caso contrário, a escola será reduzida a um mero recorte social que promove o acirramento das diferenças e da exclusão social, legitimando a classe hegemônica.

\section{A EaD como "boa" alternativa?}

A Educação a distância $(\mathrm{EaD})$ relaciona-se com a atualidade ao propor uma solução viável aos estudantes, objetivando a continuação do processo educativo, em face da recomendação de isolamento social. Porém, tal modalidade de ensino torna-se um tanto ilusória, tendo em vista a precariedade de algumas escolas públicas e a formação docente que não tratou dessa modalidade nos currículos de graduação anteriores. Logo, é fundamental compreender o papel que a EaD representa dentro do processo educativo.

Segundo Rodrigues,

No propósito de alcançar um processo comunicativo conectivo na EAD, aparece como forma de criação de outros tipos de interação, principalmente quando lança mão das novas tecnologias da comunicação em suas práticas pedagógicas. (RODRIGUES, 2011, p.79)

É sabido que a EaD representa uma excelente alternativa para oferecer conteúdos e acesso ao aprendizado aos alunos nesse período de isolamento social, pois ela representa uma modalidade de ensino que considera a distância física entre professor-aluno, buscando formas de reduzi-la. 
Compreender o "novo" processo educativo que o Brasil atravessa, em virtude da pandemia do coronavírus, possibilita uma reflexão sobre a $\mathrm{EaD}$ e como esse processo acompanha, de perto, as mudanças nos hábitos da sociedade e nos avanços tecnológicos, sem deixar de lado a vertente socioeconômica.

De acordo com Alves (2011, p. 91), “os diversos acontecimentos históricos e as variadas instituições [...] mostram que a Educação a Distância oferece oportunidades que pelo modelo presencial seria difícil ou impossível de atingir". Dessa forma, cumpre destacar que a EaD desponta como uma solução viável para os problemas ocasionados pela pandemia. Porém, o emprego dessa modalidade deve ser avaliado com parcimônia e considerando sua relação com a realidade dos alunos de escola pública.

Assim, nos aponta Costa (2017), a trajetória da EaD no Brasil é determinada por mudanças na sociedade,

A Educação a Distância passou por vários momentos históricos no Brasil, desde os cursos por correspondência até o momento atual, em que a internet é usada como meio de estabelecer a interação entre os personagens da educação, isto é, professores e estudantes. (COSTA, 2017, p.67)

Ainda como afirma Martins e Mill (2016, p. 121), “a educação a distância é uma forma de ensinar que independe do tempo e do local em que o professor e o aluno estão". Dessa forma, torna-se uma modalidade de ensino inovadora e que modifica os moldes pedagógicos vigentes até então.

Dessa forma, o cenário conturbado ocasionado pela pandemia de COVID-19 fez com que muitas escolas avaliassem sua prática pedagógica e refletissem acerca do que poderia ser proposto aos seus alunos. Algumas escolas da rede particular já possuíam plataformas de ensino on-line e a realização de aulas nessa modalidade a distância não representou um empecilho para o enfrentamento dessa crise.

Diante disso, a EaD vem se estabelecendo como uma modalidade de ensino muito promissora, pois oferece aos estudantes a possibilidade de formação e capacitação considerando suas dificuldades geográficas e de tempo. Entretanto, tal modalidade necessita de aportes tecnológicos de custos consideráveis, tornando-se pouco acessível a pessoas mais carentes.

\begin{abstract}
A utilização das tecnologias de informação e comunicação (TIC) na EAD implica mudança de comportamento de docentes, discentes e gestores. Os primeiros têm de aprender a se articular simultaneamente em diferentes níveis de ensino, por meio dos materiais didáticos que são construídos em redes de saberes significativos. Quanto aos estudantes, cabe-lhes tomar decisões sobre o andamento de seus estudos e ter iniciativa para construir suas estratégias de aprendizagem utilizando os diferentes meios midiáticos que contribuem para a interatividade. Já os gestores devem considerar a especificidade da dimensão espaço-temporal da organização do trabalho docente de um projeto de EAD, uma vez que este não pode estar pautado na forma de gestão do ensino presencial. (RODRIGUES, 2011, p.72)
\end{abstract}

Portanto, cabe asseverar que a educação a distância aparece como uma modalidade de ensino inovadora e que gera profundas mudanças estruturais e comportamentais na unidade escolar e nos atores que nela interagem. Sendo assim, fica possível postular que tal modalidade não deve ser implementada de uma hora para outra, no rompante de uma crise com as proporções da atual pandemia, mas, deve 
considerar a situação econômica que abrange a todos, bem como a formação docente e o preparo devido a ser fornecido aos estudantes e docentes para atravessarem esse momento.

Diante do cenário provocado pela pandemia, a rede pública se viu obrigada a propor alguma medida que não prejudicasse os alunos. Algumas Secretarias de Educação propuseram uma plataforma digital gratuita, na qual os alunos receberiam os conteúdos nesse período do isolamento social. Contudo, essa medida se traduz como parcialmente eficiente, uma vez que nem todos os alunos possuem arcabouço para a aprendizagem autônoma e nem tampouco a facilidade de acesso à Internet. Outras Secretarias de Educação avaliam a possibilidade de remanejamento do calendário acadêmico com reposição de aulas e priorização de conteúdos.

Torna-se um pouco incerto conceber essa modalidade de ensino na educação pública básica, tal como aponta Litto (2003):

\footnotetext{
Num processo de aprendizagem a distância são necessários perfis específicos e ela não serve para alunos desmotivados ou que precisam de muita atenção de um professor e, além disso, a educação básica brasileira não forma indivíduos plenamente preparados para uma graduação a distância. (LITTO, 2003, p. 324)
}

Além disso, vale refletir que a educação a distância deve ser uma prática que corrobora para o bom desempenho pedagógico tanto do aluno, como do professor. Entretanto, não deve ser encarada como substituta ou única. $\mathrm{O}$ aluno tem o direito de receber total apoio docente, ainda mais, em tempos de crise. Pensa-se que, o grande engano com a educação a distância seria pensá-la com uma maneira independente de oferecer aprendizagem, sem necessitar da figura de um professor, o que torna a modalidade um erro absoluto.

Assim, a educação a distância representa uma boa alternativa para as escolas particulares, e que já possuem essa ferramenta em sua organização, mas, para as escolas públicas ela representa uma opção instável, pois não foram motivadas em tempo hábil a terem essa prática em seu meio. Espera-se que, após essa crise, as escolas da rede pública possam dialogar com maior intimidade com essa modalidade de ensino de forma proveitosa e compreendendo o seu verdadeiro peso na educação no século XXI. E ainda, perceber que a figura do professor é indispensável para o processo educativo.

Ainda de acordo com Rodrigues (2011, p. 79) "não é a facilidade de deslocamento virtual ou geográfico que conseguirá inovar a educação, mas sim a clareza da concepção de educação cidadã de que cada projeto se apropria.”. Tal afirmativa dialoga com a ideia de um currículo que seja verdadeiramente inclusivo, ao passo que a educação possa despertar mudanças no paradigma social, isto é, ser um movimento que luta contra as desigualdades e não que reforce tais diferenças.

Em relação à modalidade a distância, não se pode negar o devido valor ao que compete ampliar o acesso, assim como também aponta Alves (2011), que tal forma de ensino é considerada democrática à 
medida que reduz obstáculos materiais e geográficos e atende variados alunos de forma simultânea. Contudo, por utilizar elementos tecnológicos para transpor essas barreiras, tais como: computadores, smarthphones e afins, essa modalidade torna-se cara e irreal para as realidades dos alunos de escola pública, considerando que muitos deles são carentes e ainda necessitando de aporte financeiro dos seus responsáveis.

Nesses moldes, a educação não se torna um elemento que promove a ampliação da cidadania, mas favorece e destaca as diferenças estabelecidas pela sociedade de cunho capitalista, na qual o poder aquisitivo torna-se o responsável por oferecer melhores padrões facilitadores.

A contradição entre as classes marca a questão educacional e o papel da escola. Quando a sociedade capitalista tende a generalizar a escola, esta generalização aparece de forma contraditória, porque a sociedade burguesa preconizou a generalização da educação escolar básica. Sobre esta base comum, ela reconstituiu a diferença entre as escolas de elite, destinadas predominantemente à formação intelectual, e as escolas para as massas, que ou se limitam à escolaridade básica ou, na medida que têm prosseguimento, ficam restritas a determinadas habilitações profissionais. (SAVIANI, 1994, p.08)

Portanto, assim como assevera Saviani (1994), cabe relacionar o papel da escola frente às novas tecnologias, cabendo discutir que, como se observa no contexto da pandemia do coronavírus, a educação marca a questão social dualista, dividindo e estratificando pobres e ricos, considerando apenas a capacidade de acompanhar o novo molde educativo. Com isso, é possível inferir que aqueles, que não possuem condições básicas e necessárias para acompanhar o novo modelo, ficarão à margem de uma sociedade cada vez mais desigual. Desse modo, a educação não se torna libertadora, mas segregadora.

\section{Um paralelo do contexto atual com o pensamento freireano}

Assim como o exposto anteriormente, o modelo de educação "para" todos foi um tema levantado pela classe hegemonicamente favorecida. Contudo, o modelo foi pensado com ressalvas no que diz respeito à atuação social e política da classe dominada. Pensando em mudar a forma como os trabalhadores e seus filhos poderiam atuar na sociedade, Paulo Freire inovou o jeito de ensinar e aprender, o seu método é reconhecido em diversos países e se torna atual a cada leitura, principalmente, quando confrontado com a atualidade.

É notório que Paulo Freire se sensibiliza com as mazelas sociais e se torna um defensor de políticas que visem reduzir a desigualdade e ampliar o acesso aos mais fracos e marginalizados. Por esse motivo, seus estudos iam ao encontro das necessidades populares e da luta pela transformação social a partir de um modelo educativo verdadeiramente prático e que considerava a vida do indivíduo. 
As elites dominadoras, na sua atuação política, são eficientes no uso da concepção "bancária" (em que a conquista é um dos instrumentos) porque, na medida em que esta se desenvolve uma ação apassivadora, coincide com o estado de "imersão" da consciência oprimida. Aproveitando esta "imersão" da consciência oprimida, estas elites vão transformando-a naquela "vasilha" de que falamos, e pondo nela slogans que a fazem mais temerosa ainda da liberdade." (FREIRE, 1987, p. 48)

Segundo a citação do mestre Paulo Freire, é possível compreender que a educação precisa ser libertária, tal como ele mesmo defende, ao passo em que possibilita ao sujeito traçar os rumos da própria história e, com isso, escolher o que julga melhor para si. Num modelo educativo que apregoe apenas pela memorização dos conteúdos e temas, o individuo é levado a aprender sem entender a relação estabelecida pelo saber e a sociedade. Nesses moldes, a educação não serve para oportunizar melhorias na condição de vida do aluno e propiciar autonomia no fazer e no pensar.

Entretanto, essa capacidade de autonomia só será possível quando a educação se tornar uma ferramenta de nivelamento social, na qual todas as classes possam receber o mesmo conteúdo e o mesmo modelo educativo. Caso contrário, a educação continuará sendo uma ferramenta utilizada pela classe dominadora como instrumento para se sustentar no topo da pirâmide social.

Freire (1987) ainda defende a ideia de que é fundamental:

propor ao povo, através de certas contradições básicas, sua situação existencial, concreta, presente, como problema que, por sua vez, o desafia e, assim, lhe exige resposta, não só no risível intelectual, mas não nível da ação. (FREIRE, 1987, p. 49)

Dessa forma, Freire assevera que a educação deve interagir positivamente com o contexto social, pois ela deve ser uma maneira de reduzir as desigualdades e, não apenas, servir aos interesses dos dominadores. O povo deve estar plenamente consciente do seu papel no contexto social, a fim de que possa exigir mudanças e soluções plausíveis aos problemas que enfrenta.

O texto de Paulo Freire ainda se torna atemporal quando postula que:

Frente a este universo de temas que dialeticamente se contradizem, os homens tornam suas posições também contraditórias, realizando tarefas em favor, uns, da manutenção das estruturas, outros, da mudança. [...] No momento em que uma sociedade vive uma época assim, o próprio e racionalismo mitificador passa a constituir um de seus temas fundamentais, que terá, como seu oposto combatente, a visão crítica e dinâmica da realidade que, empenhando-se em favor do seu desvelamento, desmascara sua mitificação e busca a plena realização da tarefa humana: a permanente transformação da realidade para a libertação dos homens (FREIRE, 1987, p. 53)

Portanto, o texto de Paulo Freire encontra ancoragem nos dias atuais no que tange a educação descortinar a luta desigual imposta pelos meios educacionais: privado e público. Tal combate apenas fere a real proposta da educação, que é nivelar os sujeitos como cidadão íntegros e pensantes. Supor que os modelos educativos, tanto público como privado, são equivalentes, torna-se um grande mito que precisa ser modificado. 
Por conseguinte, os escritos de Paulo Freire visam trazer à tona dos debates atuais a questão da educação emancipatória, que é capaz de promover a diferença na vida das pessoas. Todavia, uma educação que já prevê uma diferença em sua oferta, não poderá ser encarada como medida para o nivelamento social, mas, como um instrumento que reafirma a segregação social.

\begin{abstract}
Somente quando os oprimidos descobrem, nitidamente, o opressor, e se engajou na luta organizada por sua libertação, começam a cair em si mesmos, superando, assim, sua "conivência" com regime opressor. Se esta descoberta não pode ser feita em nível puramente intelectual, mas da ação, o que nos parece fundamental, é que esta não se cinge a mero ativismo, mas esteja associada a sério empenho de reflexão, para que seja práxis. O diálogo crítico e libertador, por isso mesmo que supõe a ação, tem de ser feito com os oprimidos, Qualquer que seja o grau em que esteja a luta por sua libertação. Não um diálogo às escâncaras, que provoca a fúria e a repressão maior do opressor. (FREIRE, 1987, p. 29)
\end{abstract}

Com isso, Freire (1987) postula que a libertação se dará através de um diálogo franco e aberto entre as duas classes: elite e proletariado. A reflexão sobre o contexto social deve ser notória, pois influencia ambas as classes. Logo, a prática educativa encontra-se ancorada nessa reflexão atual acerca dos problemas sociais.

Buscando ainda reforço nos escritos de Freire (1987, p. 20), é possível concluir que "a realidade social, objetiva, que não existe por acaso, mas como produto da ação dos homens, [...] transformar a realidade opressora é tarefa histórica, é tarefa dos homens."

Portanto, compreender que a educação exerce um papel socialmente importante, a coloca num patamar diferenciado: ela deve possibilitar o debate democrático, de não destacar as diferenças socioeconômicas, mas traçar alternativas eficientes de unificação e transformação da realidade opressora, na qual uma classe subjuga a outra, através do acesso dificultado à educação.

Com esse período inesperado, a educação deve prevalecer como condição de engajamento e possibilidade libertária, uma vez que se torna visível que a ciência está na vanguarda dessa crise, buscando soluções ao problema. Desse modo, impedir que uma parcela da população tenha acesso ao conhecimento é o mesmo que marginalizar tal grupo, o impedindo de ascender socialmente.

O legado de Paulo Freire é bem claro no que diz respeito a educação tornar-se ferramenta de luta contra a opressão, bem como apontando o diálogo como condição fundamental de um modelo de educação que priorize a confiança no povo e na construção conjunta. Apesar do que pode se pensar, Paulo Freire subordina a educação à política e ao contexto social, dessa forma, vislumbrando uma saída antiopressiva e organizada sob o lema da igualdade dos diferentes sujeitos sociais.

\title{
Considerações finais
}

Apesar do texto de Paulo Freire ser dedicado ao estudo de práticas de alfabetização e letramento, ele torna-se marcante para compreender a dinâmica educativa imposta pelo período social vivido em meio 
à pandemia da COVID-19: de um lado as escolas privadas servindo aos interesses de uma elite e, de outro, as escolas públicas com uma estrutura precária e buscando soluções ineficientes e fracas para sobreviver a esse momento atípico.

Desse modo, é possível compreender que a educação só será um instrumento de transformação social e emancipação do sujeito, assim como defende Demerval Saviani e Paulo Freire, quando essa oferecer uma qualidade que não serve aos interesses da elite burguesa, mas que seja pensada sem distinções. Assim como aponta Freire (1987, p. 30), "Precisamos estar convencidos de que o convencimento dos oprimidos de que devem lutar por sua libertação não é doação que eles passam a liderança revolucionária, mas resultado de sua conscientização".

Logo, nesse período de pandemia, a educação não deve destacar as desigualdades e relaxar frente às dificuldades da classe pobre, que luta para acompanhar o ensino a distância, com todas as suas especificidades de ordem tecnológica. A educação deve fornecer subsídios aos estudantes e professores para atravessarem, com êxito, essa pandemia, considerando as particularidades de cada um dos envolvidos no processo.

Embora perceba-se que a $\mathrm{EaD}$, quando empregada na educação pública básica em meio a pandemia, tornou-se uma sucessão de erros, não se pode negar a ampliação e democratização do acesso que ela exerce. Um bom exemplo disso são os cursos de graduação oferecidos pelo consórcio CEDERJ (Centro de Educação a Distância do Rio de Janeiro), que alcança milhares de estudantes com poucas condições para se deslocarem até os grandes centros urbanos a fim de se graduarem. Nesse modelo, a EaD tem caráter positivo, uma vez que o seu público já ingressa conhecendo o funcionamento e a dinâmica de tal modalidade.

Como defende Alves (2011), a EaD é considerada a mais democrática das modalidades de educação, pois transpassa obstáculos de ordem geográfica e física, chegado até o aluno.

Contudo, na educação básica, a modalidade a distância é vista, nesse período atípico que se atravessa, dando destaque às desigualdades sociais, pois as escolas públicas não possuem aporte técnico e pedagógico para proporem um modelo de ensino que seja verdadeiramente eficiente e que promova a função transformadora da sociedade. Pelo contrário, a escola pública fica à mercê dos temas tratados pelas lideranças da elite, reforçando os interesses dessa classe dominante.

Conscientes do papel social que a escola representa, torna-se inaceitável acreditar que não existe dicotomia entre a oferta de aprendizagem nos modelos públicos e privados. Dessa forma, medir os dois grupos de alunos com a mesma avaliação acaba se tornando segregador, uma vez que as escolas públicas não possuem artifícios adequados a fim de dar continuidade em seu processo educativo em meio à pandemia do COVID-19. Da mesma forma, acreditar que o grupo de alunos da escola pública tem 
obrigação de acompanhar as novas diretrizes educacionais também torna uma assertiva que advoga para o descaso com a educação pública.

Logo, é fundamental que se estude e trace métodos e alternativas para que a EaD não crie um abismo social entre as realidades das escolas públicas e privadas do Brasil. Isso seria um grande insucesso da educação brasileira, reforçando a ideia negativa de que a escola pública só forma mão-de-obra barata.

\section{Referências}

ALVES, D. A “Scholé”" como modelo predominante de educação para "todos" a partir da Modernidade e o legado da escola pública. Manuscrito IV - Origem e Legado da Escola Pública. Rio de Janeiro: Disciplina Educação e Trabalho; DFE/UNIRIO, 2019.

. Notas para o estudo do trabalho industrial urbano: o princípio educativo da 'escola para todos' a partir da modernidade. Revista Trabalho Necessário: História e historiografia em TrabalhoEducação. Niterói, RJ: UFF/FE; NEDDATE, v. 18, n. 35, p. 38-60, jan.-abr., 2020. Disponível em: $<$ https://doi.org/10.22409/tn.v18i35.40491>. Acesso em: 15.jun.2020.

ALVES, L. "Educação a distância: conceitos e história no Brasil e no mundo". Revista Brasileira de Aprendizagem Aberta e a Distância. Rio de Janeiro, RJ: UFRJ, v.10, 2011. Disponível em: $<$ http://seer.abed.net.br/index.php/RBAAD/issue/view/13/3> Acessado em 17.jun.2020

CAMPELlO, A. M. Dualidade Educacional. In: PEREIRA, I.; LIMA, J. Dicionário da educação profissional em saúde. Rio de Janeiro: EPSJV/FIOCRUZ, 2008. Disponível em: $<\underline{w w w}$.epsjv.fiocruz.br/index.php?Area=Material\&Tipo=8\&Num=43>. Acessado em 15.jun.2020.

CEDERJ. Site institucional. Disponível em: <https://www.cecierj.edu.br/cederj/> Acessado em 18.jun. 2020

COSTA, A. R. da., A Educação a Distância no Brasil: Concepções, histórico e bases legais. Revista Científica da FASETE $2017 . \quad$ Disponível $<$ https://scholar.googleusercontent.com/scholar?q=cache:czOK-gyQccIJ:scholar.google.com/ + educa $\% \mathrm{C} 3 \% \mathrm{~A} 7 \% \mathrm{C} 3 \% \mathrm{~A} 3 \mathrm{o}+\mathrm{a}+\mathrm{dist} \% \mathrm{C} 3 \% \mathrm{~A} 2 \mathrm{ncia}+\mathrm{no}+\mathrm{brasi} \& \mathrm{hl}=\mathrm{ptBR} \& a s \_\mathrm{sdt}=0,5 \&$ as $\_$ylo=2016 $>$ Acessado em 17.jun.2020

FREIRE, P., Pedagogia do Oprimido. $17^{\mathrm{a}}$ ed. Rio de Janeiro, RJ. Paz e Terra, 1987. 
FRIGOTTO, G., Trabalho. In: PEREIRA, I.; LIMA, J. Dicionário da educação profissional em saúde. Rio de Janeiro: EPSJV/FIOCRUZ, 2008. Disponível em: $<\underline{w w w . e p s j v . f i o c r u z . b r / i n d e x . p h p ? A r e a=M a t e r i a l \& T i p o=8 \& N u m=43}>$. Acessado em 15.jun.2020.

KUENZER, A. Z. Educação e trabalho no Brasil: o estado da questão. Brasília, DF: INEP; REDUC, 1991. Disponível em: < http://www.dominiopublico. gov.br/download/texto/me002671.pdf> . Acesso em: 16.jun.2020.

LITTO, F. M. Educação a distância e a USP. Jornal da USP, v. 18, p. 639, 2003. Disponível em: $<$ http://www.futuro.usp.br/producao.cientifica/rtigos/fl_eadeausp.hym>. Acesso em: 19.jun.2020.

MARTINS, S. L. B.; MILL, D. Estudos científicos sobre a educação a distância no Brasil: um breve panorama. Inclusão Social, $\quad$ v. $\quad 10, \quad$ n. $\quad 1, \quad 2016$. Disponível em: $<$ http://hdl.handle.net/20.500.11959/brapci/80297>. Acesso em: 17.jun.2020.

RODRIGUES, C. A. C. Configurações das abordagens pedagógicas da educação a distância. Revista Brasileira de Aprendizagem Aberta e a Distância. Rio de Janeiro, RJ: UFRJ, v.10, 2011. Disponível em: $<$ http://seer.abed.net.br/ index.php/RBAAD/issue/view/13/3 > Acessado em 17.jun.2020

SAVIANI, D. O trabalho como princípio educativo frente às novas tecnologias. FERRETTI, C. Novas tecnologias, trabalho e educação: um debate multidisciplinar. Petrópolis, RJ: Vozes, 1994. Disponível em: $<$ http://www.forumeja.org.br/go/files/ demerval\%20saviani.pdf $>$. Acesso em: 16.jun.2020.

. Escola: Dominação ou Transformação?. Painel sobre educação - VI Congresso da APPSindicato. Foz do Iguaçu, PR: APP-Sindicato, 26 de outubro de 1995. (Vídeo da Conferência). Disponível em: $<$ https://drive.google.com/open?id= 1zKiPebXGTe781yNdXLx4REhnMb--tsxA $>$ Acesso: 15.jun.2020.

- Trabalho e educação: fundamentos ontológicos e históricos. Revista Brasileira de Educação. Campinas, SP: Autores Associados, v. 12, n.34, jan/abr., 2007. Disponível em: $<$ https://www.scielo.br/pdf/rbedu/v12n34/a12v1234.pdf $>$. Acessado em 16.jun.2020.

\footnotetext{
${ }^{\mathrm{i}}$ Administrador, Estudante de Pedagogia (UNIRIO), Pós-graduado em Docência no Ensino Superior e Psicomotricidade, Pósgraduando em Temas e Perspectivas Contemporâneas de Educação e Ensino (CEFET/RJ) E-mail: jardeldelgado.rj@gmail.com ORCID: https://orcid.org/0000-0003-2573-1152
} 